\title{
Influence of mineral fertilizers on growth and formation of large-sized saplings of small-leaved linden (Tilia Cordata Mill.) and silver birch (Betula Pendula Roth.)
}

\author{
Khamza Yuldashev ${ }^{1 *}$, Yakubjan Yuldashov ${ }^{2}$, Ruziboy Bahramov ${ }^{1}$, and Mukhitdin Kalandarov ${ }^{2}$ \\ ${ }^{1}$ Research Institute of Forestry, 111104 Tashkent, Uzbekistan \\ ${ }^{2}$ Tashkent State Agrarian University, 100020 Tashkent, Uzbekistan
}

\begin{abstract}
This article presents the results of a study on the effect of mineral fertilizers on the growth and formation of large-sized saplings of small-leaved linden (Tilia Cordata Mill) and silver birch (Betula Pendula Roth.) in a typical sierozem of the Tashkent region. The main criterion for assessing the effect of fertilizers and the feasibility of their use is the growth of saplings. It has been established that the growth of saplings of small-leaved linden and silver birch is enhanced by the use of mineral fertilizers. At the same time, the growth rate depends on the doses and the ratio of the fertilizers used.
\end{abstract}

\section{Introduction}

Reduced field space and a lack of vital nutrient elements are contributing to the drop in productivity [1]. Fertilizer is used to control the delivery of critical elements [2,3]. Essential nutrient deficiencies have become the most common cause of yield losses [4]. The elements are required as a major factor in enhancing growth, yield, and quality, as well as a factor in lowering negative environmental impact [5-8]. It is a well-known fact that fertilizer consumption and productivity have a beneficial relationship. Fertilizers are responsible for a 50-60 percent rise in agricultural production in recent years. As a result, one of the most basic requirements for achieving the potential yield is the availability of key nutrient components. Plants primarily obtain nutrients from the soil. The optimal growth of plants is also impacted by physico-chemical-biological features of soil, such as soil texture, organic matter, cation exchange capacity, $\mathrm{pH}$, electrical conductivity, and soil microbial activity [9-12]. Chemical fertilizers are a useful input for increasing crop production, although large doses have been linked to decreased soil characteristics and crop yields over time. Organic or mineral fertilizers, such as cow manure, on the other hand, help to retain the soil's qualities [13]. When developing a technology for growing large-sized seedlings of drooping birch on irrigated lands, the use of mineral fertilizers is of great importance [14]. The results of work on the use of fertilizers in forestry in foreign countries [15-22] as well as in the Republic of Uzbekistan showed that the introduction of mineral fertilizers is one of the most important factors contributing to an increase in the stability, safety and growth rate of woody plants. The results of work on the use of fertilizers in forestry in foreign countries, as well as in our republic, scientific works [2327] showed that the introduction of mineral fertilizers is one of the most important factors contributing to an increase in the stability, safety and intensity of growth of woody plants.

Studying of assimilation issue of mineral nutrition elements in the plant growth process makes it possible to perceive the needs of seedlings in nutrients. It also allows to some extent control some physiological processes, in particular, nutritional processes in order to obtain good sustainable yields [28]. This judgment is corresponded with our research. To create a unit of dry matter, seedlings of different tree species require an unequal amount of basic elements of root nutrition. As attested to by the percentage of nutrients in various organs of linden plant [29].

\section{Materials and Methods}

In 2015-2017 We had studied the effect of mineral fertilizers on the growth of two-year-old silver birch seedlings. The method of field experiment according to B.A Dospekhov [14], laboratory analyzes according to the method "Agrochemical, agrophysical and microbiological studies of soil analysis". The climatic conditions of the area of the experimental site were given according to the data of the Tashkent meteorological station. The experiments were carried out on the territory of the research and experimental farm "Darkhan" at NIILKh on typical gray soils of the Tashkent region with humus content in the topsoil of $1.18 \%$, total nitrogen is $0.09-0.12 \%$, phosphorus is $0.15-0,18 \%$.

\footnotetext{
*Corresponding author: lion0787@gmail.com
} 
The amount of absorbed phosphorus in the arable horizon of the soil is very low $-28.0 \mathrm{mg} / \mathrm{kg}$ of soil, and also a small amount contains ammonia and nitrate forms of nitrogen $-10.2-19.0 \mathrm{mg} / \mathrm{kg}$ of soil.

\section{Results and Discussion}
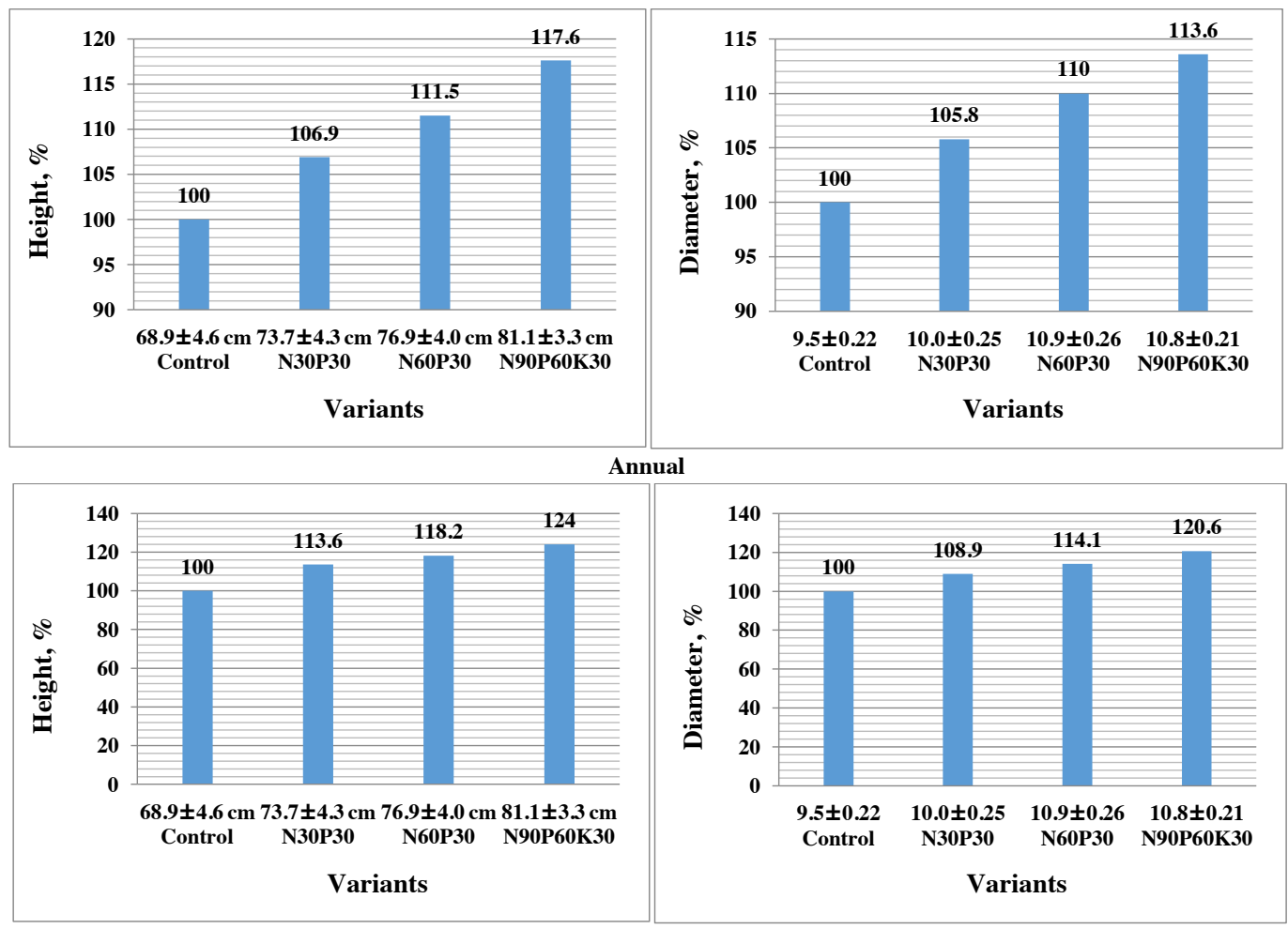

Biennial

Fig.1. Growth of one- and two-year-old seedlings of small-leaved linden, depending on mineral fertilizers

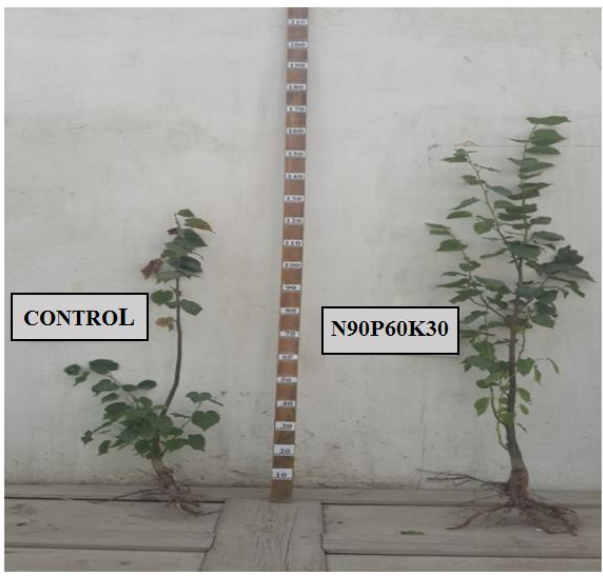

Fig.2. Two-year saplings of small-leaved linden tree fertilized with a full complex of mineral fertilizers (N90P60K30)

When developing a technology for growing large-sized seedlings of small-leaved linden and silver birch on irrigated lands, the issue of the use of mineral fertilizers is also important.The study of the effect of mineral fertilizers on the growth of two-year-old seedlings of small-leaved linden are shown in Fig. 1. The growth and development of twoyear-old small-leaved linden saplings increased significantly in the second year of their life moreover the effect of 
fertilizers during this period was more pronounced. Observations done in the second year of life of the small-leaved linden after planting show that the largest growth of two-year-old linden seedlings in height was seen in the variant with N90P60K30 (see Fig.1).

With a double feeding with nitrogen and phosphorus, where the increase in height was greater compared to the control by $24 \%$, and the diameter at the root collar by $20.6 \%$ (experimental accuracy $\mathrm{P}=3.6-2.4$ ). In the variant N60P30, where nitrogen and phosphorus were introduced with one feeding, the increase in height was $18.2 \%$ in diameter, $14.1 \%$ compared to the control (experimental accuracy $\mathrm{P}=4.2-2.0$ ).

Our observations showed that two-year-old seedlings of small-leaved linden in all variants with fertilization in comparison with the control had greener color of leaves and an increased leaf area (see Fig. 2, Table 1.). For example, on the N90P60K30 variant, the leaf apparatus was 6.6 thousand $/ \mathrm{cm}^{2}$ more per model plant than on the control variant.

Apparently, mineral fertilizers enhance the growth of the linden leaf area; thereby contributing to an increase in plant growth in height and further actively forming the crown (see Table 1).

Table 1. Influence of mineral fertilizers on the formation of crowns of two-year old seedlings of small-leaved linden (for 1 model sapling)

\begin{tabular}{|l|c|c|c|c|}
\hline \multicolumn{1}{|c|}{ Variants } & $\begin{array}{c}\text { Number of } \\
\text { branches, pcs. }\end{array}$ & $\begin{array}{c}\text { The total length of } \\
\text { the branches cm }\end{array}$ & $\begin{array}{c}\text { Number of } \\
\text { leaves, pcs. }\end{array}$ & $\begin{array}{c}\text { Leaf area, } \\
\text { thousand / } \mathbf{c m}^{\mathbf{2}}\end{array}$ \\
\hline Control & 6 & 455 & 79 & 15.9 \\
\hline N30P30 & 8 & 680 & 83 & 21.1 \\
\hline N60P30 & 9 & 692 & 89 & 24.5 \\
\hline N90P60K30 & 10 & 705 & 91 & 27.6 \\
\hline
\end{tabular}

Plants in fertilized variants not only grew better, but also developed faster. If the control trees had an average of 5-6 pcs of less developed lateral branches, then with the use of fertilizers, were 8-10 pcs, of branches. The conditions of mineral nutrition affect the accumulation of dry mass of linden seedlings and its organs. It was also observed that in the second year of growing model seedlings with the use of fertilizers there was noticeable increase in the mass of leaves, stems and roots, as well as the entire seedling in comparison with the control option by 1.5-2 times (see Table 2).

Table 2. Accumulation of dry matter by two-year old seedlings of small-leaved linden, depending on mineral fertilizers

\begin{tabular}{|l|c|c|c|c|c|c|}
\hline \multirow{2}{*}{ Variants } & \multicolumn{5}{|c|}{ Dry mass of 1 model sapling } & \multirow{2}{*}{ Root length, cm } \\
\cline { 2 - 5 } & Leaves & Stems & \multirow{2}{*}{ Root } & \multicolumn{2}{|c|}{ Total } & \multirow{2}{*}{} \\
\cline { 5 - 6 } & & & & gr & \% & \\
\hline Control n/f & 12.3 & 22.0 & 24.0 & 58.3 & 100 & 1380 \\
\hline N30P30 & 19.0 & 30.0 & 36.7 & 85.7 & 130.0 & 1492 \\
\hline N60P30 & 24.5 & 35.6 & 48.3 & 108.4 & 186.2 & 1570 \\
\hline N90P60K30 & 36.0 & 41.0 & 52.0 & 129.0 & 222.1 & 1682 \\
\hline
\end{tabular}

Table 3. The content of nitrate nitrogen and mobile phosphorus in 0-75 cm soil layer under two-year-old small-leaved linden seedlings, $\mathrm{mg} / \mathrm{kg}$ for air-dry soils

\begin{tabular}{|l|c|c|c|}
\hline \multirow{4}{*}{ Variants } & \multicolumn{3}{|c|}{ Timing of taking samples } \\
\cline { 2 - 4 } & $\mathbf{1 5 . 0 6 . 1 6}$ & $\mathbf{1 5 . 0 7 . 1 6}$ & $\mathbf{2 0 . 0 8 . 1 6}$ \\
\hline Nitrates \\
\hline N30trol & 10.7 & 6.7 & 3.2 \\
\hline N60P30 & 12.8 & 17.1 & 10.0 \\
\hline N90P60K30 & 18.0 & 19.3 & 11.2 \\
\hline \multicolumn{4}{|c|}{ Phosphorus } \\
\hline Control n/f & 21.5 & 20.0 & 12.0 \\
\hline N30P30 & 22.0 & 27.5 & 19.0 \\
\hline N60P30 & 24.1 & 30.2 & 20.7 \\
\hline N90P60K30 & 26.0 & 31.8 & 22.0 \\
\hline
\end{tabular}

This is particularly notable when applying full mineral fertilizers (N90P60K30), the dry weight of 1 model seedling was $129.0 \mathrm{~g}$ in the control variant, and this figure corresponded to only $58.3 \mathrm{~g}$, which is $122.1 \%$ of the dry weight gain. Good results were obtained in the variant with the N60P30 consumption, where the dry weight of the seedling exceeded the control variant by $86.2 \%$.Application of fertilizer favorably affects the development of root systems. As has shown by biometric measurements of the linden length taproots, in the N90P60K30 variant, their length is almost 1.5 times greater than the control, which was $1682 \mathrm{~cm}$, in relation to the control, which indicated $1380 \mathrm{~cm}$. The data of 
the conducted research shows that the linden seedlings actively form the crown under the influence of fertilizers. Because of the longer growth period; this sort by the second year of life manages to assimilate a significant part of the applied fertilizers and increase the synthesis of organic substances due to them.

To study the content of nitrates and mobile forms of phosphorus in the soil, our studies were carried out in June, during the period of increased growth of seedlings and their increased consumption of nutrients (Table 3). Under irrigation conditions, the content of nitrates and phosphates in the soil largely depends on the dose and timing of mineral fertilizers and on the growth rate of linden seedlings. For example, the amount of nitrates and phosphoric acid in June-July in the fertilized variants was higher than in the control. In this regard, on fertilized plots, seedlings grew much better and absorbed more nutrients than control plants. By the end of the growing season (August, September), their content decreases, both in the control and in the variants with the use of fertilizers, the data obtained are presented in Table 3.

Analysis of the materials obtained allows us to conclude that at different times of sampling for nitrates and phosphorus, the highest indicators were noted in variants N60P30 at the beginning and end of the growing season for nitrate $18.0 \mathrm{mg} / \mathrm{kg}$ and $11.2 \mathrm{mg} / \mathrm{kg}$, for phosphorus these values accordingly amounted to $24.1 \mathrm{mg} / \mathrm{kg}$ and $22.0 \mathrm{mg}$ $/ \mathrm{kg}$.

In the variant $\mathrm{N} 90 \mathrm{P} 60 \mathrm{~K} 30$, nitrate at the beginning and end of the growing season had values of $21.5 \mathrm{mg} / \mathrm{kg}$ and 12.0 $\mathrm{mg} / \mathrm{kg}$, for phosphorus, respectively, $26.0 \mathrm{mg} / \mathrm{kg}$ and $21.3 \mathrm{mg} / \mathrm{kg}$. And in the N30P30 variant, the indicators for the content of nitrates and phosphorus were not differ much from those in the control variant. The results of the analysis showed that the highest percentage of the main nutrients are contained in the leaves, fewer in the roots and even less in the stems. Thus, the nitrogen content at the beginning of the vegetation was $1.37 \%$, at the end $2.07 \%$. However, the highest nitrogen content was seen in July-August, which corresponded to the following indicators $3.23-3.32 \%$. The phosphorus content in the leaves at the beginning of the growing season was $0.56 \%$, at the end of the growing season $0.59 \%$. And besides that, the highest number of phosphorus in the leaves indicated in the months of July and August, respectively, $0.73-0.79 \%$. The potassium content at the beginning of vegetation was $1.26 \%$, at the end was $0.96 \%$. The highest phosphorus proportion in the leaves was in August-September. The nitrogen content in stems during the growing season varied slightly, from $1.50 \%$ at the beginning of the season to $1.65 \%$ at the end of the season. Similarly, as for phosphorus, fluctuations during the growing season were insignificant and amounted to $0.56 \%$ at the beginning of the growing season and $0.63 \%$ at the end. As for potassium, it was noted that at the beginning of the growing season its content was greater than $-1.63 \%$ than during the entire growing season. In the roots, the presence of nitrogen, potassium and phosphorus varied in minor amounts during the growing season.

The content of the main nutrients in the leaves of two-year-old saplings of small-leaved linden, depending on fertilizers, are given in Table 4.

Fertilization did not significantly affect the amount of nitrogen in the leaves of linden seedlings during vegetative growth due to their more intensive accumulation of dry matter and the effect of "dilution" taking place. Only at the end of the growing season of linden saplings in variants with fertilization of the plant was characterized by a higher accumulation of nitrogen than in the control.

Table 4. The content of the main nutrients in the leaves of two-year-old saplings of small-leaved linden, depending on fertilizers (in $\%$ of dry matter weight)

\begin{tabular}{|c|c|c|c|}
\hline \multirow[b]{2}{*}{ Variants } & \multicolumn{3}{|c|}{ Timing of taking samples } \\
\hline & 25.05 .16 & 15.07.16 & 20.08.16 \\
\hline \multicolumn{4}{|c|}{ Nitrogen } \\
\hline Control $\mathbf{n} / \mathbf{f}$ & 1.20 & 1.42 & 1.86 \\
\hline N30P30 & 1.35 & 1.40 & 1.90 \\
\hline N60P30 & 1.48 & 1.42 & 2.02 \\
\hline N90P60K30 & 1.52 & 1.53 & 2.07 \\
\hline \multicolumn{4}{|c|}{ Phosphorus } \\
\hline Control n/f & 0.40 & 0.30 & 0.27 \\
\hline N30P30 & 0.46 & 0.32 & 0.38 \\
\hline N60P30 & 0.40 & 0.38 & 0.44 \\
\hline N90P60K30 & 0.38 & 0.38 & 0.48 \\
\hline \multicolumn{4}{|c|}{ Potassium } \\
\hline Control $\mathbf{n} / \mathbf{f}$ & 1.29 & 1.34 & 1.60 \\
\hline N30P30 & 1.37 & 1.38 & 0.62 \\
\hline N60P30 & 1.48 & 1.40 & 1.68 \\
\hline N90P60K30 & 1.56 & 1.38 & 1.74 \\
\hline
\end{tabular}

So, in the control at the end of vegetation, nitrogen indicators were $1.86 \%$, in fertilized variants, it was, respectively, from $1.90 \%$ to $2.07 \%$. For phosphorus, these indicators at the end of the growing season were $0.27 \%$ in the control, and with fertilizers from $0.38 \%$ to $0.48 \%$. For potassium in the control $1.60 \%$ and with fertilization variants, these indicators ranged from $0.62 \%$ to $1.74 \%$. The pattern of phosphorus absorption during the growing season of seedlings was the same as for nitrogen, the values themselves were higher. A clear effect of fertilizers on the percentage of 
phosphorus in linden leaves was not found until July, and since August, its content slightly increased both in the fertilized and in the control variants. The maximum potassium content in the leaves of linden saplings occurs at the same time as for nitrogen and phosphorus. Fertilization had not significantly affected the potassium content in the leaves of linden seedlings during vegetative growth due to its sufficient amount in the soil. It should be noted that a high content of nitrogen, phosphorus and potassium occurs in the first months of the growing season of saplings and especially during budding and full leafing.
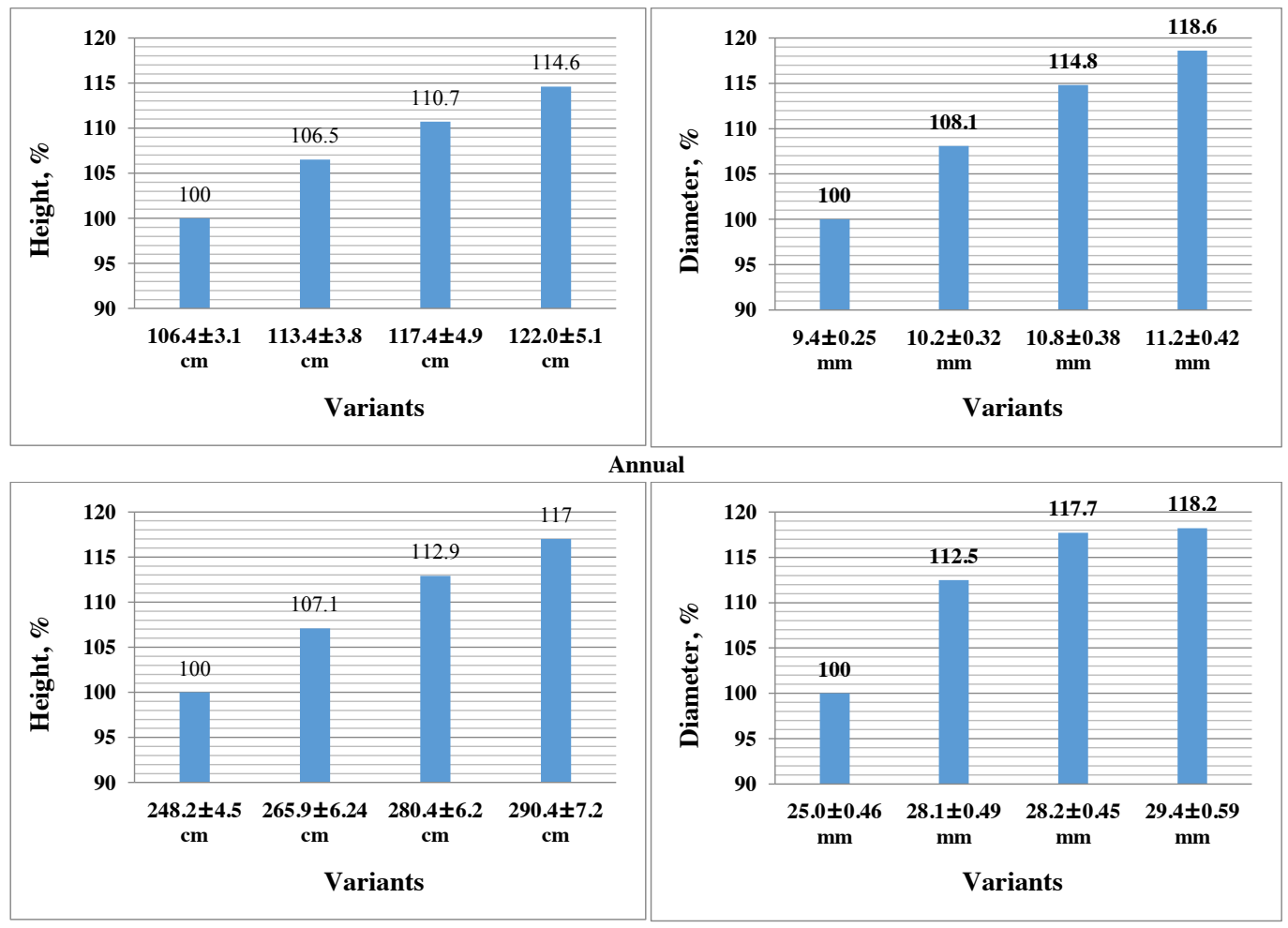

Biennial

Fig.3. Growth of one- and two-year-old silver birch saplings depending on mineral fertilizers

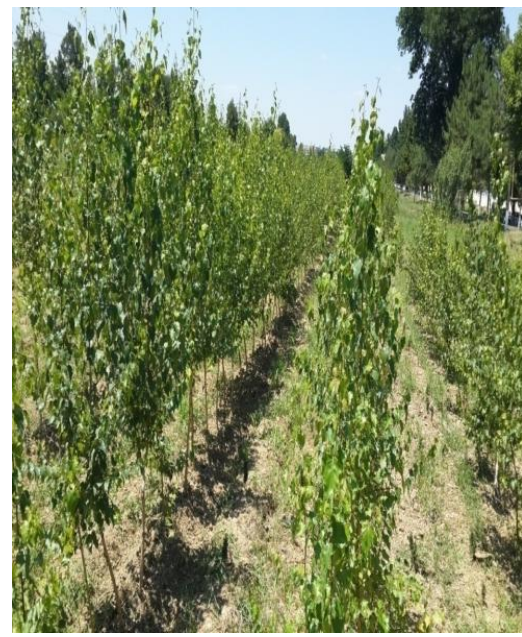

1

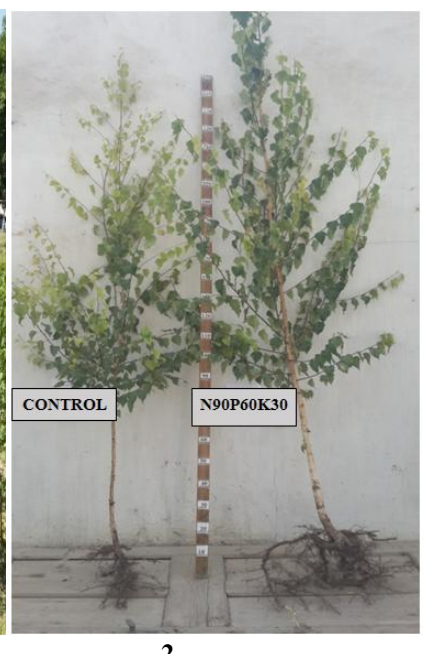

2

Fig.4. Two-year-old silver birch seedlings:1. General view of the experimental site; 2. Fertilized with a full complex of mineral fertilizers (N90P60K30) 
Consequently, fertilizing of linden saplings after planting and in the second year of life must be carried out during the budding period (late May, early June), when height growth of linden happens rapidly, which was confirmed in our studies with fractional application of full mineral fertilizer (N90P60K30).

Biometric indicators of one and two-year-old silver birch seedlings, depending on fertilizers, are given in Fig. 3 and 4. From the data shown in Fig. 3, it can be seen that mineral fertilizers had a higher positive effect on the growth of twoyear-old silver birch seedlings compared to small-leaved linden.

It was found that for the growth and formation of two-year-old silver birch seedlings, the best conditions are created when complete mineral fertilizers (N90P60K30) are applied with two-time nitrogen and phosphorus fertilization during full leafing (May) and at the beginning of height growth (second half of June) of saplings.

The saplings height, the diameter at the root collar, the dry weight, the number of shoots and leaves in general, had the highest rates in this variant. For example, the height of two-year-old birch saplings was $290.4 \mathrm{~cm}$ versus $248.2 \mathrm{~cm}$ in the control, which was an increase of $17 \%$.

In this case, the total weight of the organs of the model seedling was $1104.2 \mathrm{~g}$, the number of shoots is 30 pieces and the number of leaves is 328 pieces in comparison $805.0 \mathrm{~g} ; 18 ; 126$ appropriate controls (see Table 5).

Table 5. Accumulation of dry matter by two-year-old seedlings of silver birch depending on mineral fertilizers

\begin{tabular}{|l|c|c|c|c|c|c|c|}
\hline \multirow{2}{*}{ Variants } & \multicolumn{3}{|c|}{$\begin{array}{c}\text { Dry mass of 1 model } \\
\text { sapling }\end{array}$} & \multicolumn{2}{c|}{ Total } & \multicolumn{2}{c|}{$\begin{array}{c}\text { Length of root } \\
\text { system }\end{array}$} \\
\cline { 2 - 8 } & leaves & stems & root & g. & \% & cm & \% \\
\hline Control n/f & 231.1 & 356.0 & 218.0 & 805.0 & 100 & 181 & 100 \\
\hline N30P30 & 242.0 & 364.1 & 248.2 & 854.3 & 106.1 & 188 & 103.8 \\
\hline N60P30 & 356.0 & 378.0 & 267.0 & 1002.0 & 112.5 & 209 & 115.4 \\
\hline N90P60K30 & 358.9 & 392.3 & 350.0 & 1104.2 & 113.7 & 225 & 124.3 \\
\hline
\end{tabular}

The introduction of nitrogen and phosphorus at a dose of $30 \mathrm{~kg} /$ ha during bud opening did not have an effective impact of the growth and formation of two-year-old birch seedlings.

Somewhat better results were obtained with the introduction of N60P30 with one nitrogen fertilization (30 kg / ha) during full leafing, where the average height of two-year-old saplings was $280.4 \mathrm{~cm}$, the diameter at the root collar was $29.4 \mathrm{~mm}$ versus $248.2 \mathrm{~cm}$ and $25,0 \mathrm{~mm}$ according to the control. In addition, in the fertilized variants of twoyear-old birch saplings, they had a lively color of leaves and a large leaf surface (see Table 6).

Table 6. Formation of crowns of two-year-old silver birch seedlings depending on mineral fertilizers

\begin{tabular}{|l|c|c|c|c|c|}
\hline & Number of & The total length of & \multicolumn{3}{|c|}{ per one model sapling } \\
\cline { 4 - 6 } Vranches & the branches, cm & $\begin{array}{c}\text { Number of } \\
\text { Veaves, pcs. }\end{array}$ & $\begin{array}{c}\text { Leaf area, } \\
\text { cm }^{\mathbf{2}}\end{array}$ & $\begin{array}{c}\text { Total length of } \\
\text { roots, cm }\end{array}$ \\
\hline Control n/f & & & 126 & 4220 & 142 \\
\hline N30P30 & 18 & 210 & 210 & 5332 & 156 \\
\hline N60P30 & 21 & 282 & 240 & 8870 & 162 \\
\hline N90P60K60 & 26 & 380 & 328 & 10740 & 173 \\
\hline
\end{tabular}

Table 7. The content of the main nutrients in the leaves of two-year-old silver birch saplings, depending on fertilizers (in\% of dry matter weight)

\begin{tabular}{|l|c|c|c|}
\hline \multirow{2}{*}{ Variants } & \multicolumn{3}{|c|}{ Timing of taking samples } \\
\cline { 2 - 4 } & 25.05 .16 & 15.07 .16 & 20.08 .16 \\
\hline \multicolumn{4}{|c|}{ Nitrogen } \\
\hline Control n/f & 2.26 & 2.30 & 2.18 \\
N30P30 & 2.33 & 2.42 & 2.28 \\
N60P30 & 2.52 & 2.60 & 2.40 \\
N90P60K30 & 2.70 & 2.81 & 2.36 \\
\hline \multicolumn{4}{|c|}{ Phosphorus } \\
\hline Control n/f & 0.34 & 0.38 & 0.36 \\
N30P30 & 0.30 & 0.40 & 0.38 \\
N60P30 & 0.35 & 0.40 & 0.34 \\
N90P60K30 & 0.32 & 0.42 & 0.34 \\
\hline \multicolumn{4}{|c|}{ Potassium } \\
\hline Control n/f & 1.35 & 1.44 & 1.44 \\
N30P30 & 2.00 & 1.72 & 1.38 \\
N60P30 & 2.20 & 1.68 & 1.50 \\
N90P60K30 & 2.41 & 1.70 & 1.52 \\
\hline
\end{tabular}

For example, the leaf area per 1 model seedling was $5332 \mathrm{~cm}^{2}$ in N30P30, $8870 \mathrm{~cm}^{2}$ in N60P30, $10740 \mathrm{~cm}^{2}$ in $\mathrm{N} 90 \mathrm{P} 60 \mathrm{~K} 30$ versus $4220 \mathrm{~cm}^{2}$ of the control. Increased doses of nitrogen in most cases caused abundant branching and 
leafing, which was very important for use in landscaping. For example, in the variant N90P60K30 there were 30 pcs of branches, and in the variant N60P30 there were 26.0 pcs. of branches, in the control there were only 18 pcs. Twoyear-old birch seedlings looked like three-year old ones with a well-developed leaf apparatus and thin physiologically active roots. It should also be mentioned that planting material with an underdeveloped root system, when planted in a permanent place, does not take root well. To achieve high survival rate and good growth of young woody plants, planting material should be purposefully formed. Saplings should have a squat stem and a well-developed network of thin, physiologically most active roots. We had studied the content of nitrogen; phosphorus and potassium in the leaves of two-year-old birch saplings in order to substantiate the timing and dose of fertilization (see Table 7). The data are given in Table 7 indicate that the application of N90P60K30 contributed to an increase in the content of nitrogen and potassium in the leaves of birch seedlings. With a small dose of nitrogen ( $60 \mathrm{~kg} / \mathrm{ha})$, its content in the leaves decreases. As for the phosphorus content in the leaves, it is worth noting that it changed little depending on the applied fertilizers. Apparently the optimal amount of fertilizer, in which the nutrients were absorbed in the best way, was the N90P60K30 variant. In summary, and as mentioned earlier, the application of fertilizers in doses and ratios N90P60K30, providing the best nutritional conditions, and, accordingly, growth can be called optimal for silver birch saplings. Experiments show that linden differs from birch in less nitrogen and potassium content and more phosphorus. The application of nitrogen fertilizers in a mixture with phosphorus and potassium (N90P60K60) contributed to an increase in the content of nitrogen and potassium, a decrease in phosphorus in linden leaves.

For example, if the phosphorus content in the leaves of birch saplings against the background of nitrogen-phosphorus fertilizers (N60P30) is $0.70 \%$, while in non-fertilized plants it was $1.07 \%$.

Such a change in the ratio of nutrients assimilated by plants during the growing season had a very strong effect on the growth and development of plants. In this regard, the general condition of birch seedlings differed little from the control plants. Therefore, in the second half of the growing season, when the most intensive formation of dry matter is taking place, it is very important to fully supply birch saplings with nutrients. According to the variant with N90P60K60, where such conditions were created (feeding with nitrogen in mid-June), the plants differed from the plants of other variants in terms of branching power, high growth in height and diameter, consequently, a crown was formed that met the needs of ornamental gardening. Our data, as well as the work of other researchers reviewed in the literature review, showed that the effectiveness of fertilizers depends primarily on its dose and the ratio in the nutrient medium between nitrogen, phosphorus and potassium. For birch seedlings, there should be more nitrogen in the fertilizer than phosphorus and potassium, about one and a half and two times. In such conditions, the seedlings grow successfully and healthy.

\section{Conclusions}

In conclusion, mineral fertilizers, depending on the doses and timing of application, significantly improve the growth and condition of saplings of small-leaved linden and silver birch. In this regard, in order to accelerate the growth and development of saplings, for the first time in years of growth, they need fertilization. It should be said that the application of fertilizers in doses and ratios - N90P60K30, providing the best nutritional conditions, and, accordingly, can be called optimal for the growth and development of large-sized saplings of small-leaved linden and silver birch.

\section{References}

1. M.M. Selim, Introduction to the Integrated Nutrient Management Strategies and Their Contribution to Yield and Soil Properties, International Journal of Agronomy 2020, 2821678 (2020)

2. P.S. Bindraban, C. Dimkpa, L. Nagarajan, et al. Revisiting fertilisers and fertilisation strategies for improved nutrient uptake by plants, Biol Fertil Soils 51, 897-911 (2015)

3. S.I. Sempeho, H.T. Kim, E. Mubofu, A. Hilonga, Meticulous Overview on the Controlled Release Fertilizers, Advances in Chemistry 2014, 363071 (2014)

4. K. Goulding, S. Jarvis, A. Whitmore, Optimizing nutrient management for farm systems, Philosophical transactions of the Royal Society of London. Series B, Biological sciences, 363(1491), 667-680 (2008)

5. J.W. Dobrowolski, D. Bedla, T. Czech, F. Gambus, K. Gorecka, W. Kiszcak, T. Kuzniar, R. Mazur, A. Nowak, M. Sliwka, O. Tursunov, A. Wagner, J. Wieczorek, M. Swiatek, Integrated Innovative Biotechnology for Optimization of Environmental Bioprocesses and a Green Economy, Optimization and Applicability of Bioprocesses, eds H. Purohit, V. Kalia, A. Vaidya, A. Khardenavis, Springer, Singapore, chapter 3, pp. 27-71 (2017)

6. J.W. Dobrowolski, J. Kobylarczyk, O. Tursunov, S.Q. Toh, Integration of Local Eco-Innovation with Global Problems of Protection of the Natural Environment and Bio-Based Green Economy, In Proceedings : AASRI International Conference on Circuits and Systems (CAS), Atlantis Press, 9 25-28 (2015) 
7. N. Toshpulatov, O. Tursunov, D. Kodirov, G. Kholmuratova, Environmentally friendly technology for the destruction of tobacco mosaic viruses (TMV) from selected species of plants, IOP Conf. Ser.: Earth Environ. Sci. 614, 012133 (2020)

8. J.W. Dobrowolski, O. Tursunov, O. Pirimov, O.J. Nazarova, Laser Biotechnology for Nutritional Health, Sustainable Environment and Development, IOP Conf. Ser.: Earth Environ. Sci. 614, 012108 (2020)

9. D. Neina, The Role of Soil $\mathrm{pH}$ in Plant Nutrition and Soil Remediation, Applied and Environmental Soil Science 2019, 5794869 (2019)

10. P.P. Xue, Y. Carrillo, V. Pino, et al. Soil Properties Drive Microbial Community Structure in a Large Scale Transect in South Eastern Australia, Sci Rep 8, 11725 (2018)

11. K.L. Page, Y.P. Dang, R.C. Dalal, The Ability of Conservation Agriculture to Conserve Soil Organic Carbon and the Subsequent Impact on Soil Physical, Chemical, and Biological Properties and Yield, Front. Sustain. Food Syst. 4, 31 (2020)

12. F.J.M. O’Brien, M. Almaraz, M.A. Foster, A.F. Hill, D.P. Huber, E.K. King, H. Langford, M-A. Lowe, B.S. Mickan, V.S. Miller, O.W. Moore, F. Mathes, D. Gleeson, M. Leopold, Soil Salinity and pH Drive Soil Bacterial Community Composition and Diversity Along a Lateritic Slope in the Avon River Critical Zone Observatory, Western Australia, Front. Microbiol. 10,1486 (2019)

13. W. Hua, P. Luo, N. An, et al., Manure application increased crop yields by promoting nitrogen use efficiency in the soils of 40-year soybean-maize rotation, Sci Rep 10, 14882 (2020)

14. B.A. Dospekhov, Field experiment technique, Alliance, Moscow (2011)

15. SK. Kozhakhmetov, A.K. Khamzaev, Zh.M. Zhuraev, Use of organic and mineral fertilizers in the cultivation of Crimean (p. Pallasiana) and Oddi (p. Sylvestris) pine saplings, OOO Aster it-servis, Tashkent (2019)

16. V. V. Kutilkina, V.B. Trots, The use of mineral fertilizers when growing seedlings of ordinary ash, News of the Orenburg State Agrarian University, 3(59), 63-66 (2016)

17. A.V. Romanchuk, A.V. Yurenya, Creation of forest plantations by seedlings grown with the use of complex mineral fertilizers of prolonged action, Journal Trudy BSTU. Series 1: Forestry, Nature Management and Processing of Renewable Resources 2(210), 103-108 (2018)

18. V.B. Trots, O.A. Belousova, Application of mineral fertilizers when growing seedlings of horse chestnut, News of the Orenburg State Agrarian University 6(68), 56-58 (2017)

19. G. Singh, T. Singh, A. Singh, Effect of Fertilization on Growth of Poplar Clones in Nursery, International Journal of Bio-resource and Stress Management 10, 64-69 (2019)

20. Kh.K. Yuldashev, Mineral Fertilizers Influence on Large-Sized Seedlings Growth and Formation of Pendant Birch, International Journals of Sciences and High Technologies 12, 60-63 (2020)

21. R. Bahramov, S. Khojahmedov, D.Yuldosheva, G. Yodgorova, Technologies for growing Magnolia Grandiflora in forest nurseries, IOP Conf. Ser.: Earth Environ. Sci. 614, 012116 (2020)

22. R Bahramov, A Mamatyusupov, D. Tokhtaboeva, J Khomidjonov, H.Yuldashev, A comprehensive application of fertilizers for growing plantations in forest nurseries: A brief review, IOP Conf. Ser.: Earth Environ. Sci. 614, 012117 (2020)

23. O.A. Selishcheva, V.K. Gvozdev, Investigation of sowing qualities and efficiency of methods of preparing linden seeds for sowing, Proceedings of BSTU. Forestry 1, 166 (2015)

24. A.I.Pisarenko, V.V. Strakhov, Forestry in Russia: from use to management, Publishing House Jurisprudence, Moscow (2004)

25. V.S. Shumakov, The use of mineral fertilizers in forests, TsBNTI Leskhoz, Moscow (1971)

26. T.A. Zheltikova, Forest nurseries of Central Asia, SredazNIILH, Tashkent (1954)

27. S. Wang, H. Chen, Y. Tan, et al., Fertilizer regime impacts on abundance and diversity of soil fauna across a poplar plantation chronosequence in coastal Eastern China, Sci Rep 6, 20816 (2016).

28. V.P. Fimkin, Recommendations for improving the technology of growing planting material in irrigated nurseries, State Forestry Committee of the UzSSR, Tashkent (1977)

29. V.V. Sakhnov, Features of the development of seedlings of Scots pine (pinus sylvestris L.) and Sukachev's larch (larix sukaczewii) when using the drug "Gumiral" in forest nurseries of the Middle Volga region, Candidate of Biological Sciences Dissertation, Ufa (2007) 